\title{
The Use of Nonmonetary Incentives as a Motivational Tool in Sports
}

\author{
Tshepang Tshube \\ Michigan State University, \\ Michigan, USA
}

\author{
Dele Akpata \\ University of Botswana, Gaborone, \\ Botswana
}

\author{
Brandon Irwin \\ Kansas State University, \\ Kansas, USA
}

\begin{abstract}
This study examined the extent to which athletes are motivated by social and tangible nonmonetary incentives. Junior (ages 13-18) and elite (19 and above) athletes (190 males and 180 females) from different clubs in Botswana responded to a questionnaire assessing their perceptions of and the extent to which they were motivated by tangible (e.g., cars and scholarships) and social (e.g., media coverage and praise from leaders, e.g., president) nonmonetary incentives. Results showed that Botswana athletes placed significant value $(p<0.001)$ on both tangible and social nonmonetary incentives regardless of gender and age. Also, results indicated that the level of importance on both tangible and social nonmonetary incentives varied by sport. Boxing reported the least value $(M$ $=1.85)$ on the importance of social nonmonetary incentives while volleyball reported the highest value $(M=2.80)$. Netball reported the least value $(M=2.33)$ on tangible nonmonetary incentives while basketball reported the hightest mean $(M=3.21)$. Results suggest that nonmonetary incentives may be a useful supplement to monetary incentives in motivating athletes to win medals, particularly in Africa where economies are struggling. Results are discussed within the self-determination theory.
\end{abstract}

Keywords: nonmonetary, social incentives, tangible incentives, motivation, monetary incentives, self-determination theory

\section{Introduction}

The debate on the use of external rewards for intrinsic motivation has been going on for over three decades (Amorose \& Horn, 2000; Amorose, Horne, \& Miller, 1994; Butler, 1987; Cameron \& Pierce, 1994; Deci, 1971; Eisenberger \& Cameron, 1996; Ryan \& Deci, 2000; Vallerand \& Rousseau, 2001). Rather than address the literature on the longer and long-standing debate between extrinsic vs. intrinsic motivation, this paper provides an account of how monetary, nonmonetary, and social events are significantly valued as motivational tools among athletes in Botswana. The interpretation of external rewards affects intrinsic motivation as either informational or controlling (Ryan \& Deci, 2000). Countries use monetary rewards and social events to motivate athletes to win medals at major games. Athletes have been promised cars and a lot of money if they win medals for their counties at major games, such as the Commonwealth Games, the World Championships, and the Olympics. The Ugandan government had put forward $\$ 5,000$ as a reward to every gold medal winner at

Tshepang Tshube, Ph.D. candidate, Department of Kinesiology, Michigan State University.

Dele Akpata, Ph.D., Department of Physical Education, University of Botswana.

Brandon Irwin, Ph.D., Kinesiology Department, Kansas State University. 
the London 2012 Olympics. Motivation crowding effect theory relies on the idea that there is a psychological process which underlies intrinsic motivation and extrinsic incentives (Crifo, Diaye, \& Greenan, 2004). Monetary rewards may thus reduce intrinsic motivation: Where individuals perceive an external intervention to be controlling, and their intrinsic motivation to perform the task diminishes (Deci \& Ryan, 1985).

Success in sports may be dependent on many different factors, but athletes' motivation is the most significant factor that determines success and influences behavior in sports. Motivation depends on individuals' expectations about their ability to perform tasks and receive desired rewards (Yavuz, 2004). Ryan and Deci (2008) argued that human beings can be proactive and engaged or, alternatively, passive and alienated, largely as a function of the social conditions in which they develop and function. Research guided by self-determination theory emphasizes the social contextual conditions that facilitate vs. forestall the natural processes of self-motivation and healthy psychological development. Achievement goal theory explains that the need for competence can be realized within the sport context, and each athlete's motivation is shaped by different goals and behaviors, which athletes considered to be the best way to achieve success in sport (Miquelon \& Vallerand, 2008).

An Olympic medal is the ultimate success a country would like their athletes to achieve. Botswana just won its first Olympic medal, an $800 \mathrm{~m}$ men silver medal. The Olympic athletes who stand on the podium represent only the tip of the iceberg of the Olympic glory. Olympic athletes serve as role models and mentors for thousands of young athletes. Botswana won its first World Championship medal in 2011. Amantle Montsho won the $400 \mathrm{~m}$ women, winning Botswana's first medal at the World Games after the Commonwealth Games. It took Botswana over 40 years to win an Olympic medal. The poor performance of Botswana's national teams led the government to appoint a commission of enquiry in 1997. The commission investigated the cause of the poor performance by national teams in international level games, such as the Olympics Games, the All Africa Games, and even regional competitions at the Southern Africa level. The commission discovered that lack of motivation was a major cause of poor performance of Botswana national teams. Lack of incentives was also discovered as a major cause of the lack of motivation to perform at international games. In order to increase athletes' level of motivation, the commission called for providing athletes with incentives to motivate athletes to win medals at the international level. The commission proposed that the government name streets after athletes and build a wall of fame to highly motivate current and upcoming athletes to win medals for Botswana. The BNSC (Botswana National Sports Council) responded by instituting an incentive scheme. This incentive scheme was aimed at promoting and encouraging excellence at international level. The incentive schemed recognizes the outstanding performances of national teams and athletes at official regional, continental, and world competitions sanctioned by the BNSC by giving athletes rewards. The introduction of the incentive scheme was to create a motivational climate for athletes to win medals.

As mentioned earlier, winning medals in sports depends on several factors, some of which include economic, demographic, political, and climatic conditions (Ball, 1972; Bernard \& Busse, 2004; Levine, 1973; Lui \& Suen, 2007; Moosa \& Smith, 2004). Robust economies afford countries the right financial muscle to set medal targets and finance training programmes that are crucial for winning medals at international games. The medal target for Botswana at the 2011 All Africa Games in Maputo, Mozambique, was to win 20 medals, but the team was at least able to scoop 16 medals with a team of 96 athletes. Each athlete who wins a gold medal at the All Africa Games in Botswana is rewarded with a P3,000 (\$398) cheque. The main question is: What is the extent to which this cheque motivates athletes to win medals for Botswana? Mallett and Hanrahan (2004) 
argued that an athlete's motivation is very critical, but what is more critical is the understanding of what exactly motivates athletes. Having a clear understanding of what motivates athletes accords the coach an opportunity to design appropriate motivational climate in order to realize an athlete's physical talent.

Motivation and the use of rewards as a motivational tool for success have been widely studied in sports psychology (Ambrus \& Egorov, 2009; Browning \& Burr, 2009; Bucciol, Montinari, \& Piovesan, 2011; Crifo et al., 2004; Dommeyer, Curt, Hirao, Ikeda, Linkletter, \& Watanabe, 2010; Gould, Feltz, Horn, \& Weiss, 1982; Hellandsig, 1998; Mallett \& Hanrahan, 2004).

A former NBA (National Basketball Association) basketball star, Tim Hardaway, was promised a huge bonus if he made a lot of assists in games. The bonus was entirely based on passing the ball. Hardaway passed the ball a lot, particularly towards the end of the season. When interviewed, the former start admitted that to get his bonus, he had sometimes passed even when he should have shot the ball. He was highly driven by the monetary bonus. Hardaway is a typical example of the effects of rewards in sports.

Given incentives, athletes will do what they are told to do in order to get the monetary incentive. "Show me the medal" was a slogan introduced by the Chinese Sports Department in order to best capture the spirit of the Chinese sports apparatus. Leung and Yang (2006) observed that following China's relatively poor showing in the 1988 Olympics in Seoul, the National Sports Administration in 1991 gave 16 sports "key Olympic sport" status, which implied favorable treatment in funding and other forms of institutional support. Athletes were promised a lot of incentives for winning medals. Following the adjustments in how China rewarded national athletes, athletic success brought fame and financial bonuses for Chinese athletes and potential upward mobility for coaches and officials. China had won only five gold medals at the 1988 Seoul Olympics. China moved from five gold medals to 16 gold medals at the 1992 Barcelona and Atlanta, respectively. The incentive rewards are not only evident in China, athletes in different tournaments earn a substantial amount of financial prizes. The All England Club awarded a total of $£ 14,600,000(\$ 25,318)$ in prize money to competitors at the 2011 Championships. The Men's and Ladies' Singles Champions each received $£ 1,100,000$. Chan, Courty, and Hao (2009) confirmed that prize money has been significantly used to motivate athletes to win. Nearly $\$ 21$ million in prize money was awarded in international track and field competitions in 2004. The literature has also showed that not only money motivates athletes to win in sports, there may be other rewards that athletes value and appreciate (An example would be athletes being honoured to have dinner with the president of the country). Providing athletes with special incentives creates a positive environment for the athletes. A positive environment gives an opportunity for athletes to exert more effort hence to win medals. Hill and Pavetti (2000) showed that low income working parents often have difficulty in devoting enough time and money to pleasurable activities with their family. Providing social and tangible nonmonetary incentives, such as a ticket to a movie or an amusement park, summer camp for children, etc., may have great value for athletes. Giving such free tickets to athletes' families can be a motivation for athletes to win medals. This will give parents an opportunity to watch their kids as a result of getting free tickets. On the other hand, athletes would probably hesitate to spend a cash incentive of the same value for these kinds of activities rather than necessities. Nonmonetary incentives provide a tangible symbol of achievement and it becomes something physical to show off (Yavuz, 2004). These incentives are more relevant in a middle income country like Botswana, where families do not have a budget for recreational activities. Extending incentives that include parents is a good gesture that athletes in Botswana value.

Palomino and Rigotti (2002) analyzed the dynamic model of strategic interaction between a professional 
sport league that organizes a tournament, the teams competing to win it, and the broadcasters paying for the rights to televise it. Athletes in Botswana have significantly agreed that they are motivated by both monetary and nonmonetary incentives. Televised games are also a motivation given the situation in Botswana where soccer and sometimes volleyball and netball are the only sports that are broadcasted live. Other sports need to be accorded the same opportunity in order to enjoy the same publicity. To affirm that monetary incentives play a significant role in motivating players to win, Palomino and Rigotti (2000) observed that in professional sports, revenue sharing increases future demand for the sport, hence, increasing the revenues of the league and its players. The authors further argued that revenue sharing is based on the idea that if there are no prizes for winning, the teams' profits are independent of the competition's outcome. In other words, without a prize, there are no monetary incentives for a team to win. Mallett and Hanrahan (2004) investigated what drives some athletes to achieve at the highest level while other athletes fail to perform to their physical potential. One of the questions that Mallett and Hanrahan (2004) asked was "Why does the 'fire' burn so brightly for some elite athletes and not for others?" The research answered these questions to get a good understanding of an athlete's motivation. Athletes' personal goals and highly driven hunger for achievement are the primary determinant for success. It is therefore crucial for sports organizations to understand athletes' goals in order to provide relevant incentives. A very strong sense of self-belief was discovered as a significant factor in influencing behavior and the need for success in athletes. It is worth noting that self-confidence and self-efficacy are some of the most cited factors that are associated with athletic performance. Feltz (1985) showed that self-confidence plays a critical role in athletes' success. Lack of self-confidence seems to be closely associated with athletic failure. Confidence is therefore a very significant factor in distinguishing unsuccessful athletes from those that are successful. Mallett and Hanrahan (2004) observed that athletic identity also plays a significant role in athletes' achievement. Athletic identity is defined as the degree to which an individual identifies with the athlete's role (Brewer, 1993). Athletes with high identity tend to be highly motivated, spend more time with their team mates, and see their future defined by sports.

\section{Hypotheses}

The main hypothesis for this study was that the perceptions of Botswana athletes (athletes of Botswana) on the value of nonmonetary incentives as a motivational tool in sports are not significant.

The following subhypotheses were tested:

(1) Botswana athletes place no significant value on the role of social and tangible nonmonetary incentives as a source of motivation;

(2) There is no significant age difference in the percieved value of social and tangible nonmonetary incentives;

(3) There is no significant gender difference in the percieved value of social and tangible nonmonetary incentives;

(4) Athletes' perceptions of the value of social and tangible nonmonetary incentives do not vary by sport.

\section{Method}

A total of 370 Botswana junior (13-18 years old) and elite (19 years old and above) athletes (190 males and 180 females) from various clubs in Botswana participated in the study by completing a survey questionnaire. An online statistical software sample size calculator was used to determine the sample size. 
Based on a population size of approximately 1,146 athletes, a sample size of 400 participants was needed to conduct a survey with a confidence level of $95 \%$ and a confidence interval of $+/-4$. Six major sports in Botswana were given first preference to participate in the study: soccer, athletics, netball, volleyball, boxing, and karate. These sports are the Botswana National Sports Council's key sports, and they have more popularity and following than any other sport in the country. Some of these sports included players that participated at Olympic level. The study had a total of 10 sports, of which six came from the major sports. Simple random sampling was used to select the remaining four sports. Names of the remaining sports were put in a box and the researcher picked four from the box.

Athletes were further stratified to select each athlete from each sport. There were two strata: gender and category. Junior athletes represented one strata of the category while senior athletes represented the other. Gender balance was observed. Forty athletes from each sport participated in the study, 20 males and 20 females. The age range of athletes in the junior category ranged from 13 to 18 , while the senior athletes were 19 and above. A total of 40 athletes from each of the 10 sports were then selected using the convenience sampling method to participate in the study.

\section{Procedure}

Data collection was through a questionnaire survey administered by the researcher during competitions, training camps, and in schools. Athletes from the selected codes train and compete throughout the year, and they were readily available and willing to participate in the study. Both written and verbal instructions were provided for the survey questions. Subjects were also informed of purpose of the study by a consent letter, which was attached to the questionnaire. Respondents were asked to complete the survey anonymously. Completion of the survey took approximately 15 minutes.

The questionnaire used in the study was constructed by the researcher to meet the specific demands of the research. The language was made simple so that it would be understandable to athletes including those who do not have a high school education. The questionnaire had three sections: The first section was on social nonmonetary incentives; the second section was on tangible nonmonetary incentives and monetary incentives; and the last section solicited demographic information. Respondents were asked the extent to which available incentives motivate them to win medals. A total of 24 questions were answered by participants using a 4-point Likert type response scale ranging from " 1 = Strongly disagree" to " 4 = Strongly agree". The reliability of the questionnaire was calculated using Cronbach's Alpha estimate, which is the statistical procedure for reliability analysis. The reliability statistics for the tangible nonmonetary incentives and monetary incentives was 0.844 , and for social nonmonetary incentives it was 0.739 . The questionnaire was pilot tested on 10 athletes in sports that did not participate in the study. Appropriate revisions were made where necessary for the validity of the instrument. The questionnaire was also reviewed by two professors in sports psychology and one professor in sports management.

\section{Results}

The problem this study investigated was Botswana athletes' perceptions of the use of monetary and nonmonetary incentives as a motivational tool in sport. What included in the study was determining the extent to which athletes perceive tangible and social nonmonetary incentives as motivational tools. Since the main hypothesis for this study is the perceptions of Botswana athletes on the value of nonmonetary incentives as a 
motivational tool in sports, the following subhypotheses were tested:

H1: Botswana athletes place no significant value on the role of social and tangible nonmonetary incentives as a source of motivation.

The survey results, however, indicated that all types of incentives (social, tangible, and monetary) were perceived to be significantly motivating Botswana athletes to win medals $(p<0.01)$. The null hypotheis was rejected. Social incentives were the least important while monetary incentives were most important. All types of incentives were significantly different from one another. Monetary incentives had the highest mean $(M=$ $3.31, S D=0.96)$, followed by tangible nonmonetary incentives $(M=2.90, S D=0.98)$, and lastly social nonmonetary incentives $(M=2.42, S D=0.92)$. A standard scale of $1-4$ designed by the reseracher was used in this study $(M=2.5)$. Both monetary and tangible incentives were above the mean while social incentives were below the mean. A one sample $t$-test was conducted to assess monetary incentives signicance $(D F=368, p<$ 0.001). Monetary incentives reported the highest value $t_{(65.70)}$ CI95 $=(3.21,3.41)$, followed by tangible nonmonetary incentives $t_{(56.44)} \mathrm{CI} 95=(2.80,3.01)$ and social nonmonetary incentives $t_{(50.31)} \mathrm{CI} 95=(2.80,2.52)$.

$\mathrm{H} 2$ : The hypothesis that there is no significant age difference in the perceived value of social nonmonetary incentives was rejected in this study $(p=0.033)$.

Junior athletes (13-18 years old) had the lowest mean $(M=2.32, S D=-0.96)$, CI95 $=(2.20,2.46)$. Seniors athletes (19 years and above) had a higher mean $(M=2.55, S D=-0.89)$, CI95 $=(2.40,2.67)$. The survey indicated significant age difference with respect to social nonmonetary incentives. Senior athletes perceived social nonmonetary incentives to be more motivating than junior athletes did. An in-between subject effects reported $\left(r_{\text {adj }}=0.010\right), F_{(4.56)} \mathrm{DF}=(3.68)$.

H3: The hypothesis that there is no significant gender difference on the perceived value of social and tangible nonmonetary incentives was supported by the results.

The hypothesis was therefore not rejected.

H4: The hypothesis that athletes' perceptions of the value of social and tangible nonmonetary incentives do not vary by sport was rejected.

Results indicated that the perceived importance of social incentives significantly varied by sport. Boxing rated lower $(M=1.85)$ than basketball $(M=2.48)$, track and field $(M=2.55)$, table tennis $(M=2.80)$, and volleyball $(M=2.80)$, but these sports were not significantly different from karate, swimming, netball, and soccer. The study also found that basketball, athletics, table tennis, and volleyball were not significantly different from each other, but were more significantly higher than boxing. The importance of tangible nonmonetary incentives differed significantly by sport. Netball differed significantly from other sports (netball $<$ boxing $=$ volleyball $=$ basketba $=$ basketball, and tebble tennis $=$ soccer $=$ swimming $=$ karate $)$.

\section{Discussion}

The purpose of this study was to examine the extent to which Botswana athletes are motivated by social and tangible nonmonetary incentives. It is found that Botswana athletes placed significant value $(p<0.001)$ on both tangible and social nonmonetary incentives regardless of gender and age. Also, results indicated that the level of importance placed on both tangible and social nonmonetary incentives varied by sport. Research on motivation (Amorose \& Horn, 2000; Amorose et al., 1994; Butler, 1987; Cameron \& Pierce, 1994; Eisenberger \& Cameron, 1996; Ryan \& Deci, 2000; Vallerand \& Rousseau, 2001) over the past three decades has demonstrated that individuals are different in what motivates them to achieve. Results in this 
study will be discussed with relevance to the self-determination theory. The self-determination theory has increasingly been used as a framework for understanding motivation in sport and physical activity. According to the self-determination theory, Ryan and Deci (2000) depicted that interpersonal events are primary in the influence of intrinsic motivation. Ryan et al. (2000) defined intrinsic motivation as inherent satisfaction or pleasure associated with an activity itself. The authors used the words internally controlling and internally informational to refer to events that occur within a person. Internally, informational events (e.g., self-reward) increase perceived competence hence maintain or increase intrinsic motivation. In contrast, internally controlling (e.g., self-imposed pressure) may decrease autonomy and intrinsic motivation. The most critical component is the function of the meaning attached to the reward. Deci et al. (2000) further observed that the functional significance or salience of the event dictates whether intrinsic motivation is facilitated or diminished. The use of an external reward (e.g., money or a medal) may be perceived as a positive indicator to competence. In this case, it is perceived to be information, whereas another athlete may perceive the same reward as cohesion to keep an athlete involved in the activity (controlling). Results from this study confirm the literature that extrinsic incentives may be perceived differently by different athletes. In the case of Botswana athletes, winning a medal or other prestige-related medals might contribute to a sense of relatedness in which it is perceived to bring Botswana citizens together. This might override any "controlling" effects that this has on motivation and self-determination regulation.

To further discuss motivation and sports, coaches often wonder why some athletes are more highly motivated than others. Mallett and Hanrahan (2004) observed that one of the dominant themes in elite athletes' motivation is an intense commitment to achieve personal goals. Personal goals vary according to athletes' preferences. An athlete achieving personal goals provides them with a sense of accomplishment which, in turn, positively influences self-determination forms of motivation (Mallett \& Hanrahan, 2004). Ryan and Deci's (2000) self-determination theory on rewards explains that the relationship between the reward and intrinsic motivation is determined by how athletes interpret or perceive the reward. If the reward is perceived as informational, the reward will increase athletes' intrinsic motivation. If athletes in Botswana perceive scholarships and cars as informational, they will be intrinsically motivated to exert the full effort, which influences performance. Given the results of this study, tangible and social nonmonetary incentives are viewed as informational. Elite and junior athletes in Botswana place significant value on cars, scholarships, and media coverage. Given struggling economies in Africa, nonmonetary incentives can be used to supplement monetary incentives, particularly if athletes place significant value on them. The theory also explains that incentives can be viewed as controlling. If athletes perceive incentives as controlling, the fact that they interpret the reward as controlling will decrease their intrinsic motivation, and hence then performance. A decrease in intrinsic motivation implies incompetence, and in that regard, athletes will not exert full effort, which reduces performance. It should be noted that if athletes need incentives or rewards to perform, lack of such rewards can lead to decreased intrinsic motivation and not continue playing sport or not exert full effort. Athletes in Africa have on several occasions complained that they are not rewarded adequately. A typical example in Botswana is where athletes resigned from the national team in protest of lack of incentives. Botswana's national softball team boycotted a tournament upon arriving in Lesotho, complaining that they did not have proper attire befitting the magnitude of that tournament (Southern African Championships). 


\section{Conclusions}

It is therefore imperative that incentives be used but with full understanding that they can either decrease or increase intrinsic motivation depending on how they are being perceived. Further studies should focus more on examining athletes' motives more closely and within the self-determination theory or other theoretical frameworks to determine how these incentives affect motivation.

\section{References}

Ambrus, A., \& Egorov. (2009). Delegation and nonmonetary incentives. Mimeo: Harvard University.

Amorose, \& Horne. (2000). Intrinsic motivation: Relationships with collegiate athletes' gender, scholarship status, and perceptions of their coaches' behavior. Journal of Sport \& Exercise Psychology (JSEP), 22(1), 63-84.

Amorose, Horne, \& Miller. (1994). Intrinsic motivation in collegiate athletics: Relationship with athletes' scholarships status and coaching behaviors. Journal of Sport \& Exercise Psychology, 16, 26.

Ariely, Dan, Anat, \& Bracha. (2009). Doing good or doing well? Image motivation and monetary incentives in behaving prosocially. American Economic Review, 99(1), 544-555.

Ball, D. W. (1972). Olympic Games competition: Structural correlates of national success. International Journal of Comparative Sociology, 13, 186-200.

Bernard, B., \& Busse, A. (2004). Who wins the Olympic Games: Economic resources and medal totals. Review of Economics and Statistics, 86, 413-417.

Brewer, M. B. (1993). Self-identity and specific vulnerability to depressed mood. Journal of Personality, 61, 343-364.

Browning, G., \& Burr, F. (2009). Monetary and non-monetary SWO retention bonuses: An experimental approach to the combinatorial retention auction mechanism (CRAM). (MBA Professional Report, Naval Postgraduate School)

Bucciol, A., Montinari, N., \& Piovesan, M. (2011). Do not trash the incentive! Monetary incentives and waste sorting. In Harvard Business School working paper (pp. 11-93).

Butler, R. (1987). Task-involving and ego-involving properties of evaluation: Effects of different feedback conditions on motivational perceptions, interest, and performance. Journal of Educational Psychology, 79, 474-482.

Cameron, J., \& Pierce, W. D. (1994). Reinforcement, reward, and intrinsic motivation: A meta-analysis. Review of Educational Research, 64, 363-423.

Chan, W., Courty, P., \& Hao, L. (2009). Suspense: Dynamic incentives in sports contests. Economic Journal, 119, 24-46.

Courty, P., \& Hao, L. (2007). Suspense: Dynamic incentives in sports contests. The Journal of Business, 72, 545-572.

Crifo, P. M., Diaye, A., \& Greenan, N. (2004). Why do firms evaluate individually their employees? Economie et Prévision, 4, $27-55$.

Deci, E. L. (1971). Effects of externally mediated rewards on intrinsic motivation. Journal of Personality and Social Psychology, $18,105-115$.

Deci, E. L., \& Ryan, R. M. (1985). Intrinsic motivation and self-determination in human behavior. New York: Plenum.

Deci, E. L., \& Ryan, R. M. (2008). Facilitating optimal motivation and psychological well-being across life's domains. Canadian Psychology, 49, 14-23.

Dommeyer, Curt, J., Hirao, Ikeda, Y., Linkletter, \& Watanabe. (2010). Using a contingent, nonmonetary incentive to increase the response rate to a personally-initiated. Marketing Bulletin, 21, 1-9.

Eisenberger, R., \& Cameron, J. (1996). Detrimental effects of reward: Reality of myth? American Psychologist, 51, $1153-1166$.

Feltz, D. L. (1985). Appropriate use of awards. In P. Vogel, \& K. Blase (Eds.), Essentials of coaching youth ice hockey: Associate coaches' manual (pp. 339-344). Colorado Springs, AHAUS.

Gould, D., Feltz, D. L., Horn, T., \& Weiss, M. R. (1982). Reasons for attrition in competitive youth swimming. Journal of Sport Behavior, 5, 155-165.

Hellandsig, E. T. (1998). Motivational predictors of high performance and discontinuation in different types of sports among talented teenage athletes. International Journal of Sport Psychology, 29, 27-44.

Hill, H., \& Pavetti, D. (2000). Using incentives to promote job retention and advancement: Guidance from the performance improvement industry. Washington, D. C.: Mathematica Policy Research.

Leung, A., \& Yang, D. L. (2006). Global institutions, domestic incentives, and governance in China: The politics of anti-doping. Center for International Business Tuck, School of Business, Dartmouth College. 
Levine, N. (1973). Why do countries win Olympic medals? Some structural correlates of Olympic Games success. Sociology and Social Research, 29, 353-360.

Lui, H. K., \& Suen, W. (2007). Men, money and Olympic medals (Working Paper).

Mallett, C., \& Hanrahan, S. (2004). Elite athletes: Why does the "fire" burn so brightly? Psychology of Sport and Exercise, 5, $183-200$.

Miquelon, P., \& Vallerand, R. J. (2008). Goal motives, well-being, and physical health: An integrative model. Canadian Psychology, 49, 241-249.

Montinari, \& Piovesan. (2011). Do not trash the incentive! Monetary incentives and waste sorting. In Harvard Business School working paper (pp. 11-93).

Moosa, I. A., \& Smith, L. (2004). Economic development indicators as determinants of medal winning at the Sydney Olympics: An extreme bounds analysis. Australian Economic Papers, 43, 288-301.

Palomino, F. A., \& Rigotti, L. (2000). The sport league's dilemma: Competitive balance versus incentives to win (Discussion Paper 2000-109). Center for Economic Research, Tilburg University.

Ryan, R. M., \& Deci, E. L. (2000). Self-determination theory and the facilitation of intrinsic motivation, social development, and well-being. American Psychologist, 55, 68-78.

Vallerand, R. J., \& Rousseau, F. L. (2001). Intrinsic and extrinsic motivation in sport and exercise: A review using the hierarchical model of intrinsic and extrinsic motivation. In R. N. Singer, H. A. Hausenblas, \& C. M. Janelle (Eds.), Handbook of sport psychology (2nd ed., pp. 389-416). New York: Wiley.

Yang, D., \& Leung, A. (2006). The politics of sports anti-doping in China: Crisis, governance and international compliance. China: An International Journal, 6, 121-148.

Yavuz, N. (2004). The use of non-monetary incentives as a motivational tool: A surver study in a public organisation in Turkey. Middle East Technical University. 